\title{
Minority Turnout and Representation under Cumulative Voting. An Experiment.*
}

\author{
Alessandra Casella ${ }^{\dagger} \quad$ Jeffrey Da-Ren Guo ${ }^{\ddagger} \quad$ Michelle Jiang ${ }^{\S}$
}

April 30, 2021

\begin{abstract}
Under majoritarian election systems, securing participation and representation of minorities remains an open problem, made salient in the US by its history of voter suppression. One remedy recommended by the courts is Cumulative Voting (CV): each voter has as many votes as open positions and can cumulate votes on as few candidates as desired. Theory predicts that $\mathrm{CV}$ encourages the minority to overcome obstacles to voting: although each voter is treated equally, CV increases minority's turnout relative to the majority, and the minority's share of seats won. A lab experiment based on a costly voting design strongly supports both predictions.
\end{abstract}

${ }^{*}$ We thank Pedro Dal Bó, Olivier Compte, Giovanna Invernizzi, Antonin Macé, Jacopo Perego, Gergely Ujhelyi, and participants to the NBER Political Economy Spring 2021 Meeting, Columbia University Microeconomic Theory Colloquium, and Columbia Experimental Lunch for their comments. We acknowledge with gratitude the financial support of Columbia's Program for Economic Research and Experimental Lab for the Social Sciences. The experiment was approved under Columbia IRB Protocol AAAS8614.

†Columbia University, NBER and CEPR, ac186@columbia.edu.

$\ddagger$ Columbia University, jeffrey.guo@columbia.edu

$\S$ Columbia University, michelle.jiang@columbia.edu 
"And so the world watches America-the only great power in history made up of people from every corner of the planet, comprising every race and faith and cultural practice - to see if our experiment in democracy can work. [...] The jury's still out." (Obama, 2020, p. xvi).

\section{Introduction}

The fragility of American democracy, rooted historically in slavery, manifests itself in persistent efforts to disenfranchise racial and linguistic minorities, Black Americans first and foremost. Almost 60 years after the Voting Rights Act (VRA), minorities' access to the polls remains bitterly disputed, a sharp reminder of the crucial importance of voters' participation. In 2013, the Pew Research Center concluded: "The Growing Electoral Clout of Blacks Is Driven by Turnout" ". Guaranteeing high electoral participation by minorities requires rules about fair and equal access to voting. ${ }^{2}$ But that is not enough. The Pew report corresponds to the surge in Black political engagement during the Obama elections of 2008 and 2012: political participation follows the realistic chance of a desired outcome. For groups who find themselves repeatedly on the minority side, America's majoritarian electoral system makes this difficult.

Under VRA litigation, the courts have mandated modifications to electoral rules in jurisdictions where majoritarian systems effectively disenfranchise the minority. One such remedy is Cumulative Voting: a long-established voting rule that combines the advantages of at-large elections, free from gerrymandering and the dubious legality of majority-minority districts, with the realistic possibility of minority representation. CV was used for more than 100 years, from 1870 to 1980 , to elect representatives to the Illinois State House and is the rule now in tens of local jurisdictions. Outside local politics, it is used to elect corporate boards in approximately $10 \%$ of S\&P 500 companies. ${ }^{3}$

As noted already by Charles Dodgson (aka Lewis Carroll) in 1884, the core idea is to vary the number of votes that voters can cast for each candidate. Under

\footnotetext{
${ }^{1}$ Pew (2013), p.1. Black non-Hispanic turnout increased from from $60 \%$ to $65 \%$ to $67 \%$ from 2004 to 2008 to 2012 (Census Bureau, 2017).

${ }^{2}$ For a brief panoramic summary of voter suppression in the US and the role of the VRA, see Grofman et al. 1992.

${ }^{3}$ See Bowler et al. 2003 for a short history of CV. Other useful sources are Bowler et al. 1999, Engstrom 2010, Pildes and Donoghue 1995. For a strong defense of CV, see Guinier 1994. Updated information on the current use of CV is reported in fairvote.org.
} 
$\mathrm{CV}$, each voter has as many votes as there are open seats, and the candidates with more votes win, as under simple plurality. However, each voter is allowed to distribute the votes freely among any number of candidates. CV treats every voter equally; yet, a cohesive minority can ensure itself some victories by cumulating its vote.

Empirically, CV correlates with an increase in the number of elected minority representatives (Brockington et al. 1998, Bowler et al., 2003), and in the public goods provided to minority communities (Pildes and Donoghue, 1995). In addition, its use appears to increase minority participation in the political system (Bowler et al., 2001). Evaluating these empirical results, however, is complicated by the non-random adoption of $\mathrm{CV}$ : CV typically follows voting rights litigation, indicating heightened sensitivity to minority representation and stronger minority involvement.

The historical evidence then must be accompanied by experimental testing. It is such testing that we conduct in this paper. Higher observed minority turnout under CV is usually attributed to more optimistic prospects of affecting the electoral outcome. In the lab, the hypothesis maps directly into an experiment where payoffs depend on one's own group achieving electoral success but voting is individually costly. Do participants, particularly participants on the minority side, overcome those costs more often when votes can be cumulated?

The costly voting model we implement is the classic tool for studying instrumental voting (Riker and Ordeshook 1968, Palfrey and Rosenthal 1983, Ledyard 1984). The model does not explain the level of turnout observed in large elections, but captures well the comparative statics properties of different elections: turnout is predicted to increase when elections are closer, when they are more salient, when voting costs are lower, when the electorate is smaller. It is this type of comparative effect that interests us: does minority turnout increase when the voting rule changes to CV?

We run different experimental treatments, comparing standard one-voteper-open-seat voting and CV, and varying both the number of seats and the relative size of the minority. For all our parametrizations, theory suggests that CV should increase the minority's turnout relative to the majority's, as well as the fraction of seats won by minority candidates. Both predictions are satisfied in every case. The experiment confirms CV's potential to increase both the minority's turnout and its electoral success.

Previous laboratory experiments on CV (Gerber et al., 1998, and Cooper and Zillante, 2012), focus on the coordination problem it poses and ignore the ques- 
tion of turnout. We take the opposite approach. Historically, CV's coordination problem is deferred to the parties' leadership and addressed primarily through the leaders' choice of the number of party candidates. ${ }^{4}$ Once the correct number of candidates is chosen, distributing votes equally is an easy default for voters and often, as in the cases we study, maximizes electoral success. ${ }^{5}$ Inspired by such experiences, we test CV by presenting the experimental subjects with an exogenously given, theoretically optimal, number of candidates; if they decide to vote, their votes are shared equally over their party's candidates. Our focus is fully on the turnout decision. Closer to us, then, are experiments that concentrate on turnout, and especially on relative turnout for groups of different sizes (Levine and Palfrey, 2007). Because CV is an example of "semi-proportional" voting rules-rules that approach proportional representation without a proportional electoral system-particularly relevant is the experiment in Herrera et al. (2014), comparing turnout under single-winner majoritarian and proportional elections, and qualifying the commonly held belief that turnout is higher in the latter case.

The American electoral system has been fashioned by its British roots and by the founders' resolution to hamper the emergence of factions. Both have resulted in opposition to proportional representation. Electoral rules like CV have the potential to afford representation to groups that often do share common goals but can be confined to permanent minority status by majoritarian voting. Such rules can do so without the rigidity and arbitrariness of majority-minority single member districts, or of quota systems. They deserve more study.

\section{Base Model}

An electorate of $N$ potential voters selects $K>1$ representatives for a commission. Each position is identical to the others, and all positions are simultaneously decided in the election. The $N$ voters are divided into two parties: $\mathrm{M}$, the majority party with $M$ members, and $\mathrm{m}$, the minority party with $m<M$ members, where $M+m=N$. Parties are led by party leaders whose role is to propose the party's list of candidates.

\footnotetext{
${ }^{4}$ The literature is rife with colorful examples of leaders' fast learning after mistakenly nominating too many or too few candidates (Bowler et al., 1999, Sawyer and MacRae, 1962, Pildes and Donoghue, 1995).

${ }^{5}$ Sawyer and MacRae (1962) and Goldburg (1994) document that equal spreading of votes over all party candidates was the norm during the long experience of CV in the Illinois State House, where behavior likely converged to incorporate CV's lessons.
} 
Party leaders and voters share the same objective: to maximize the number of positions won by their party. The utility derived from one's party winning $k$ positions is $u(k)$, increasing in $k$. We denote by $V$ the value of controlling all positions and assume $u(k)=(k / K) V$. Linearity captures the simple objective posited above and simplifies both the lab implementation and the theoretical analysis. We adopt it on substantive grounds as well: any "place at the table" has value. Effective power in the committee is proportional to the number of seats a party has won.

Each voter has $K$ votes, and the $K$ candidates with most votes are elected. If there are ties, after the highest voted candidates are elected, the remaining open positions are filled by selecting winners randomly among the tied candidates. We call $x_{p}$ the profiles of votes cast by members of party $p$, where $x_{i p}^{k}$ is the number of votes cast by voter $i \in p$ for candidate $k$, and $x_{i p}$ the vector of all votes cast by $i$.

We study two electoral systems, multi-seat plurality (MP), and cumulative voting (CV). Under MP, each voter casts at most one vote for each candidate: $x_{i p}^{k} \in\{0,1\}$ for all $i, k$, and $p$, and each party nominates $K$ candidates. Under $\mathrm{CV}$, each voter can distribute the $K$ votes in any manner the voter desires, as long as the overall budget of $K$ votes is satisfied: $\sum_{k} x_{i p}^{k} \leq K$. The possibility of cumulating votes creates a coordination problem that party leaders help address by selecting the number of candidates, $G$ for the majority party, and $g$ for the minority party. In line with historical experience ${ }^{6}$, we allow for fractional votes, but voters, candidates, and positions are constrained to be integers.

The game has two stages. In the first stage, party leaders announce the party list; in the second stage, voters distribute their votes over the party candidates. We focus on equilibria in weakly undominated strategies where voters cast all their votes and cast votes on party candidates only. Under MP, each voter casts one vote for each party candidate. Under CV, the equilibrium is a pair of vote profiles $\left\{x_{\mathrm{M}}(G, g), x_{\mathrm{m}}(G, g)\right\}$ and a pair of party lists $\left\{G\left(x_{\mathrm{M}}, x_{\mathrm{m}}\right), g\left(x_{\mathrm{M}}, x_{\mathrm{m}}\right)\right\}$ such that each party member's votes maximize the number of seats won by the party, given the parties' lists and the other voters' voting choices, and each party list maximizes the number of seats won by the party, given the opposite party's list and all voters' voting choices.

\footnotetext{
${ }^{6}$ For example, half votes were allowed in the Illinois State House; half, third, and quarter votes are allowed in the Peoria, IL elections.
} 


\subsection{Minority representation without voting costs}

With no reasons to abstain and no leeway in distributing votes, under MP, party $\mathrm{M}$ wins all seats: each $\mathrm{M}$ candidate receives $M$ votes, and each $\mathrm{m}$ candidate receives $m<M$ votes.

CV grants the minority the possibility of winning some seats. Suppose for example that all voters in party $\mathrm{m}$ concentrate all their votes on a single candidate, who thus receives $m K$ votes. The minority wins a seat if its candidate beats the weakest of the majority candidates. If the majority attempts to win all seats, the weakest majority candidate will have most votes when the $M K$ total majority votes are distributed equally among $K$ majority candidates, and each receives $M K / K=M$ votes. Hence the minority can guarantee itself a seat if $m K>M$, or $m>M / K$. This ratio, known as the threshold of exclusion, is a fraction of $M$ : for example, a minority that is half the size of the majority can guarantee itself a seat if the number of open seats is three or more.

How many seats can the minority guarantee itself? Building on the logic just described, academics and lawyers have developed a handy formula that applies to our problem. ${ }^{7}$ Given $K, M$, and $m$, party $\mathrm{m}$ can guarantee itself $z$ seats, and party $\mathrm{M} K-z$ seats, where:

$$
\begin{aligned}
& z=0 \\
& z \in\left(\frac{K m-M}{M+m}, \frac{K m+m}{M+m}\right) \\
& \text { if } m<M / K \\
& \text { if } m>M / K \text { and } \frac{K m-M}{M+m} \notin \mathbb{Z}_{+} \\
& z=\left\{\begin{array}{ll}
\frac{K m-M}{M+m} & \text { with prob } m /(M+m) \\
\frac{K m+m}{M+m} & \text { with prob } M /(M+m)
\end{array} \text { if } m \geq M / K \text { and } \frac{K m-M}{M+m} \in \mathbb{Z}_{+}\right.
\end{aligned}
$$

The formula is well-known but seems not to answer the real question we are interested in: not how many seats can each party guarantee itself, but how many seats will each party win, taking into account the strategic interactions between party leaders, and between party leaders and voters? And yet, in our setting the two answers must coincide:

\footnotetext{
${ }^{7} \mathrm{CV}$-calculators can be found online. See, for example, https://www.lawjock.com/tools/cumulative-voting-calculator/, or Wikipedia. Early influential references in political science are Cole (1950), Glasser (1959), Sawyer and MacRae (1962), Brams (1975), and Glazer et al. (1984). For ease of reference, we derive the formula for our case in the appendix.
} 
Proposition 1. In the absence of voting costs, for all $m, M>m$, and $K$, in all equilibria of the $C V$ voting game party $m$ wins $z$ seats, with $z$ given by (1).

Proof. The proposition follows because the coincidence of goals between party leaders and members makes the game a two-player game, and the linearity of $u(k)$ renders the game constant-sum. The CV formula yields the number of seats won by each party when following its maximin strategy. In two-player constant-sum games, although multiple equilibria are possible and indeed exist in our case, all equilibria payoffs must equal the payoffs from the players' maximin strategies.

Proposition 1 thus implies that there always is an equilibrium with $g=$ $\left\lfloor\frac{K m+m}{M+m}\right\rfloor, G=K-\left\lceil\frac{K m-M}{M+m}\right\rceil$, and $x_{i m}^{k}=K / g, x_{i M}^{k}=K / G$. In the absence of voting costs, $\mathrm{CV}$ makes it possible for the minority to win some seats, in contrast to the monopoly of power granted to the majority under MP. But in realistic applications a crucial question is turnout. We extend the model to include voting costs.

\section{$3 \quad$ Voting costs}

Suppose now that each voter $i$ faces a cost of voting $c_{i}$, drawn randomly and independently across voters from a common distribution $F(c)$ with support $[\underline{c}$, $\bar{c}$ ]. Realized costs are private information, but the distribution $F(c)$ is common knowledge and does not depend on party affiliation. The cost $c_{i}$ represents the cost of going to the polls and is independent of the number of votes cast. A voter whose party wins $k$ positions has utility $U_{i}(k)$, given by:

$$
U_{i}(k)= \begin{cases}u(k)-c_{i} & \text { if voter } i \text { voted } \\ u(k) & \text { if voter } i \text { abstained }\end{cases}
$$

\subsection{Multi-winner plurality (MP)}

Under MP, voters who have turned out cast a single vote for each of the party's $K$ candidates. Although multiple positions are in play, the analysis mirrors closely the standard approach to costly voting in single winner elections. ${ }^{8}$

\footnotetext{
${ }^{8}$ Arzumanyan and Polborn (2017) study costly voting with multiple candidates but a single winner. Our model is closer to the traditional two-candidate, one-winner set-up, with each party list being the parallel to the party candidate.
} 
Call $S_{p}$ the number of voters who turn out for party $p$. Each $\mathrm{M}$ candidate receives $S_{\mathrm{M}}$ votes, and each $\mathrm{m}$ candidate receives $S_{\mathrm{m}}$ votes. Thus only three outcomes are possible: either $S_{\mathrm{M}}>S_{\mathrm{m}}$, and all $K$ positions are won by $\mathrm{M}$ candidates; or $S_{\mathrm{M}}<S_{\mathrm{m}}$, and all $K$ positions are won by m candidates; or $S_{\mathrm{M}}=$ $S_{\mathrm{m}}$, and all $K$ positions are tied, with $K$ majority and $K$ minority candidates all having the same number of votes. Under a tie, the $K$ winners are chosen randomly among all tied candidates. We denote by $E u_{T}^{M P}$ the expected utility gain from winning seats under MP in case of a tie. Then:

$$
E u_{T}^{M P}=\sum_{k=0}^{K} \frac{\left(\begin{array}{c}
K \\
k
\end{array}\right)\left(\begin{array}{c}
K \\
K-k
\end{array}\right)}{\left(\begin{array}{c}
2 K \\
K
\end{array}\right)} u(k)=V / 2
$$

where the second equality follows from $u(k)=(k / K) V$.

As in single-winner elections, a voter from party $p$ facing opposite party $p^{\prime}$ must weigh her cost of voting against the expected utility gain from influencing the outcome. Denoting by $S_{-i p}$ the number of voters who turn out in party $p$ ignoring $i$, voter $i$ can influence the outcome either by breaking ties (when $S_{-i p}=S_{p^{\prime}}$; an event with probability denoted by $\pi_{p}^{T}$ ) or by making ties (when $S_{-i p}=S_{p^{\prime}}-1$, with probability $\pi_{p}^{T-1}$ ). Thus the thresholds $\left\{c_{\mathrm{M}}, c_{\mathrm{m}}\right\}$ solve the system of equations:

$$
\begin{aligned}
c_{\mathrm{m}} & =\left[u(K)-E u_{T}^{M P}\right] \pi_{\mathrm{m}}^{T}+\left[E u_{T}^{M P}-u(0)\right] \pi_{\mathrm{m}}^{T-1}=(V / 2) \pi_{\mathrm{m}} \\
c_{\mathrm{M}} & =\left[u(K)-E u_{T}^{M P}\right] \pi_{\mathrm{M}}^{T}+\left[E u_{T}^{M P}-u(0)\right] \pi_{\mathrm{M}}^{T-1}=(V / 2) \pi_{\mathrm{M}}
\end{aligned}
$$

where $\pi_{p}\left(c_{p}, c_{p^{\prime}}\right)=\pi_{p}^{T}+\pi_{p}^{T-1}$ is the pivotal probability for a voter of party $p$.

The linearity of the utility function implies that the equilibrium equations (2) and (3) do not depend on $K$. The problem is then formally identical to the classic costly voting problem with a single winner and two alternatives. It is well-known, and we leave the expressions for the pivot probabilities to the appendix. Given equilibrium $\left\{c_{\mathrm{m}}, c_{\mathrm{M}}\right\}$, we can derive the probabilities of winning different numbers of positions. The derivation is straightforward, and again is left to the appendix.

\subsection{Cumulative voting ( $\mathrm{CV})$}

With voting costs, the game cannot be reduced to the two party leaders. It now has three stages: a nomination stage, when the leaders choose the number of candidates; a turnout stage, when, after observing privately the realization of 
the voting cost, each voter decides whether or not to vote; and finally a voting stage, when voters at the polls choose how to cast their votes.

We focus on a semi-symmetric perfect Bayesian equilibrium such that within each party, all voters follow the same strategy. We denote by $x_{-i p}$ the profile of votes cast by voters other than $i$ who turned out and belong to $p$. The equilibrium is a pair of party lists $\{g, G\}$, a pair of cost thresholds $\left\{c_{\mathrm{M}}, c_{\mathrm{m}}\right\}$, and a pair of voting profiles $\left\{x_{\mathrm{M}}, x_{\mathrm{m}}\right\}$ such that: (i) at the voting stage, conditional on voting, voter $i$ in party $p$ sets $x_{i p}\left(G, g, c_{M}, c_{m}, x_{-i p}, x_{p^{\prime}}\right)$ so as to maximize the expected number of positions won by $p$; (ii) at the turnout stage, all $i \in p$ with $c_{i}<c_{p}\left(G, g, c_{p^{\prime}}, x_{M}, x_{m}\right)$ strictly prefer to vote, and all $i \in p$ with $c_{i}>$ $c_{p}\left(G, g, c_{p^{\prime}}, x_{M}, x_{m}\right)$ strictly prefer to abstain; and (iii) at the nomination stage, the two party leaders set $g\left(G, x_{M}, x_{m}, c_{M}, c_{m}\right)$ and $G\left(g, x_{M}, x_{m}, c_{M}, c_{m}\right)$ so as to maximize their party's expected number of positions. ${ }^{9}$

For any positive turnout, if $g<K$, party $\mathrm{M}$ is guaranteed $\min [G, K-g]$ seats, and similarly, if $G<K$, party $\mathrm{m}$ is guaranteed $\min [g, K-G]$ seats. The positions contested are $g+G-K$. In the absence of voting costs, equilibria with non-contested positions are possible; not so when voting is costly because increasing the number of candidates would be weakly dominant for either party. If voting is costly, in all equilibria $G+g>K$.

We discuss the derivation of the equilibrium cost thresholds, and thus turnout, and then present the theory's numerical predictions for a set of parameters that includes those we use in the experiment. In deriving the equilibrium cost thresholds, we conjecture an equilibrium with equal spreading of votes: $x_{i \mathrm{~m}}^{k}=K / g$, $x_{i \mathrm{M}}^{k}=K / G$. We then verify that in all our parametrizations the conjecture is indeed a best reply for a voter at the polls.

For given $g$ and $G$, equilibrium cost thresholds continue to trade off costs of voting and expected utility gains from influencing the election. As before, a voter may break an existing tie or cause a tie, but if the party's candidates are fewer than the number of seats, by casting more than a single vote on each, the voter may also move the outcome from a loss to a win of all contested positions. Consider the problem for $i \in \mathrm{M}$. By voting, $i$ breaks a tie if $(K / G) S_{\mathrm{M}-\mathrm{i}}=$ $(K / g) S_{\mathrm{m}}$, or $S_{\mathrm{M}-\mathrm{i}}=S_{\mathrm{m}}(G / g) ; i$ causes a tie if $(K / G)\left(S_{\mathrm{M}-\mathrm{i}}+1\right)=(K / g) S_{\mathrm{m}}$, or $S_{\mathrm{M}-\mathrm{i}}=S_{\mathrm{m}}(G / g)-1$. In addition, voter $i$ can shift M from losing to winning all contested positions if both $(K / G) S_{\mathrm{M}-\mathrm{i}}<(K / g) S_{\mathrm{m}}$ and $(K / G)\left(S_{\mathrm{M}-\mathrm{i}}+1\right)>$ $(K / g) S_{\mathrm{m}}$, or $S_{\mathrm{M}-\mathrm{i}} \in\left(S_{\mathrm{m}}(G / g)-1, S_{\mathrm{m}}(G / g)\right)$. Denoting by $\pi_{p}^{W}$ the probability

\footnotetext{
${ }^{9}$ Note that party leaders influence turnout indirectly through the number of candidates, recalling models of leaders' enforced social norms in voting (Levine and Mattozzi, 2020).
} 
that the votes of a member of party $p$ move party $p$ from losing to winning all contested positions, if $c_{\mathrm{M}} \in(0,1)$ and $G+g>K, c_{\mathrm{M}}$ must solve:

$c_{\mathrm{M}}=\left[u(G)-E u_{T, \mathrm{M}}^{C V}(G, g)\right] \pi_{\mathrm{M}}^{T}+\left[E u_{T, \mathrm{M}}^{C V}(G, g)-u(K-g)\right] \pi_{\mathrm{M}}^{T-1}+[u(G)-u(K-g)] \pi_{\mathrm{M}}^{W}$

where:

$$
E u_{T, \mathrm{M}}^{C V}(G, g)=\sum_{x=0}^{G} u(x)\left(\begin{array}{c}
G \\
x
\end{array}\right)\left(\begin{array}{c}
g \\
K-x
\end{array}\right) /\left(\begin{array}{c}
G+g \\
K
\end{array}\right)=\frac{G}{g+G} V
$$

Or:

$$
c_{\mathrm{M}}=\frac{V(g+G-K)}{K}\left[\frac{G}{g+G} \pi_{\mathrm{M}}^{T}+\frac{g}{g+G} \pi_{\mathrm{M}}^{T-1}+\pi_{\mathrm{M}}^{W}\right]
$$

The problem is analogous for minority voters. The equilibrium condition for an interior threshold $c_{\mathrm{m}}$ is:

$$
c_{\mathrm{m}}=\frac{V(g+G-K)}{K}\left[\frac{g}{g+G} \pi_{\mathrm{m}}^{T}+\frac{G}{g+G} \pi_{\mathrm{m}}^{T-1}+\pi_{\mathrm{m}}^{W}\right]
$$

The pivot probabilities and the probabilities of winning different numbers of positions in case of ties can be derived as under MP, taking into account that the number of candidates, in each party, may differ from the number of seats. We leave them to the appendix.

Given (4) and (5), and $x_{i \mathrm{~m}}^{k}=K / g, x_{i \mathrm{M}}^{k}=K / G$, we can find party leaders' optimal choice of $G$ and $g$; given $G$ and $g$ and (4) and (5), we can verify that $x_{i \mathrm{~m}}^{k}=K / g, x_{i \mathrm{M}}^{k}=K / G$ are indeed best responses. ${ }^{10}$

\subsection{Equilibria for the experimental parametrizations}

Figure 1 shows the equilibrium turnout rates in the two parties, and the expected fraction of seats won by the minority under the two voting systems. The first column corresponds to MP, the second and third to $\mathrm{CV}$ (for $K=2$ and $K=4$, respectively. Recall that $K$ does not affect outcomes under MP). In each panel, the horizontal axis corresponds to different values of $M$, while upper and lower panels refer to different relative sizes of the two parties. ${ }^{11}$

\footnotetext{
${ }^{10}$ If $G+g=K+1$, equal spreading of votes is a best reply for any $c_{\mathrm{m}}, c_{\mathrm{M}}$. Both parties must compete to elect the weakest of their candidates, and when others spread their votes equally, strengthening the weakest party candidate amounts to spreading votes equally as well.

${ }^{11}$ We found a unique equilibrium in all cases. Recall that with $F$ uniform, $c_{p}$ corresponds to the expected turnout rate in party $p$. We discuss in the appendix the surprising lack of a consistent underdog effect $\left(c_{\mathrm{m}}>c_{\mathrm{M}}\right)$ in the MP model. For both MP and CV, raising $K$ to 6
} 

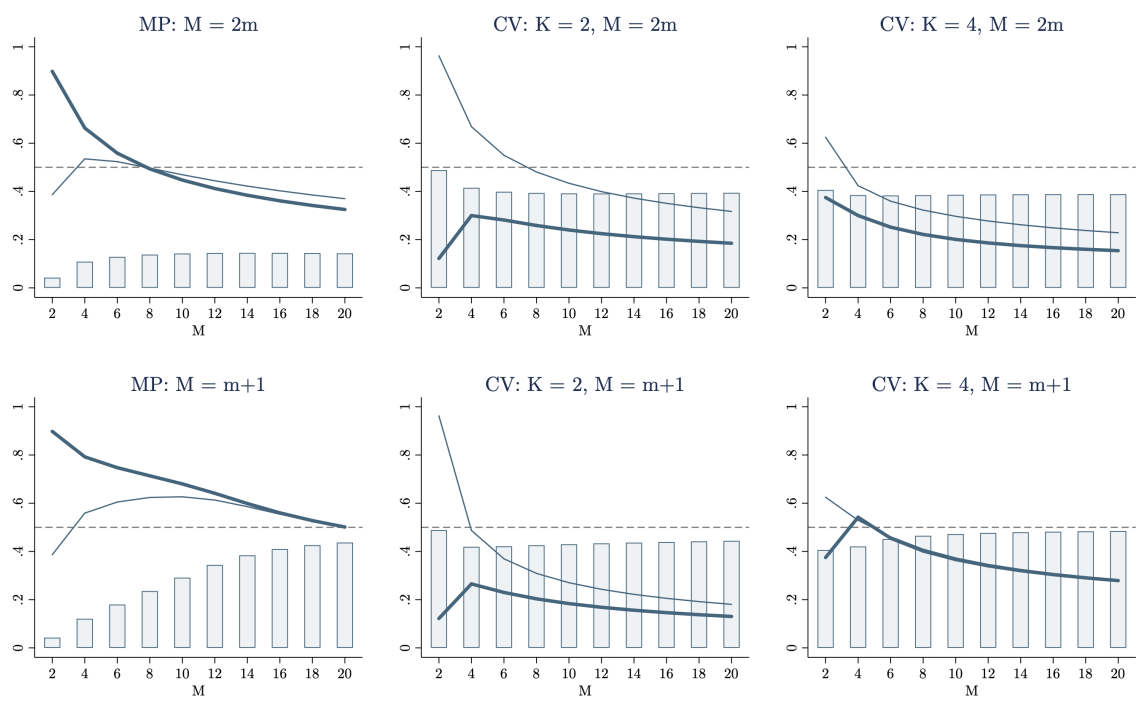

Figure 1: Expected turnout rates and share of minority seats, MP and $C V$. The thick lines correspond to $c_{\mathrm{M}}$, the thin lines to $c_{\mathrm{m}}$; the bars correspond to the expected share of minority seats. $F$ is uniform over $[0,1] ; V=4$.

The figure highlights two main regularities. First, CV consistently increases the relative turnout of the minority: whether the relative size of the two parties is large or small, whether the number of open seats is just enough for $\mathrm{CV}$ to differentiate itself from MP $(K=2)$ or is higher $(K=4)$, the ratio $c_{\mathrm{m}} / c_{\mathrm{M}}$ is higher under CV than under MP. This remains true whether the electorate is small or large, unless the difference in size of the two parties becomes negligible (for $M=m+1$ and large $M$ ), and turnout equalizes for the two parties under both MP and CV. Second, the expected fraction of seats won by the minority is consistently higher under CV. The effect is most striking when the minority is relatively small $(M=2 m)$, and its expected share of seats never rises above $14 \%$ under MP (less than half its share of the electorate) as opposed to being consistently close to $40 \%$ under CV.

The difference in outcomes between MP and CV is driven by the difference in the number of candidates. In all cases, the minority party sets $g<K$ under CV; when $G=K$, the minority's cumulation of votes results in a higher probability of affecting the outcome, incentivizing turnout; when $G<K$, the difference in does not change the qualitative results. 
turnout probabilities is reduced, but the share of minority victories is boosted by the seats left uncontested by the majority. In the figure, when $K=2$, $G=K=2$, but $g=1$ for all $M$ and $m$; when $K=4, G=3$ always; $g=2$ if $m=M / 2 ; g=3$ otherwise. Thus in the lower right panel, $g=G=3$, and the two parties' turnout probabilities converge, but the uncontested seat keeps the share of expected minority victories higher than under MP.

We can compare the results to minority victories in the absence of voting costs, and thus of turnout effects. Under MP, as we know, the minority never wins any seat, as opposed to the small but positive share predicted with voting costs. Under $\mathrm{CV}$ and costless voting, the expected share of minority victories is $1 / 2$ if $m=M-1>1$, and either $1 / 3$ (if $K=2$ ) or $1 / 4$ (if $K=4$ ) if $m=M / 2$. Accounting for turnout thus softens the impact of relative party size, reducing expected minority victories for $m=M-1$, but increasing them for $m=M / 2$. Under $\mathrm{CV}$, the minority achieves substantive representation but is always expected to maintain its minority status in the allocation of seats.

\section{The Experiment}

The experiment reproduces exactly the theoretical model. Our main focus is the comparison between turnout, for both parties, and the fraction of minority victories under the two voting rules, MP and CV. To evaluate the robustness of the results and to test the power of the theoretical framework, we implemented four different parametrizations: while we kept $M=4$ throughout the experiment, we varied $m$ between 2 and 3 ; for each $m$, we set $K=2$ and $K=4$. In all treatments, voting costs were drawn independently across participants from a uniform distribution with support $[0,100]$, and $V$, the value of controlling all positions, was set at 400 .

The number of candidates fielded by each party under CV was set at the theoretically optimal value for each parametrization and we constrained voters who turned out to spread their votes equally over their party candidates. While strong, the constraint is the most reasonable option in our setting. Not only is equal spreading of votes part of the equilibrium but in the absence of distinguishing features among candidates or seats, and of any coordinating device, variations in the distribution of votes would simply reflect noise. Participants acted as eligible voters: at each round, each drew an independent voting cost and decided whether or not to vote. The design thus mimics the numerical sim- 


\begin{tabular}{lccc|ccc|cc}
\hline \hline & & & & & & $\begin{array}{c}\text { Exp. Min. } \\
\text { Seats }\end{array}$ & $\begin{array}{c}\text { Exp. Min. } \\
\text { Share }\end{array}$ \\
\hline \hline 4,2 & 2 & MP & 2,2 & 0.54 & 0.66 & 0.81 & 0.22 & 0.11 \\
4,2 & 2 & CV & 2,1 & 0.67 & 0.30 & 2.23 & 0.84 & 0.42 \\
& & & & & & & & \\
4,2 & 4 & MP & 4,4 & 0.54 & 0.66 & 0.81 & 0.44 & 0.11 \\
4,2 & 4 & CV & 3,2 & 0.42 & 0.30 & 1.41 & 1.52 & 0.38 \\
& & & & & & & & \\
4,3 & 2 & MP & 2,2 & 0.56 & 0.79 & 0.71 & 0.24 & 0.12 \\
4,3 & 2 & CV & 2,1 & 0.49 & 0.27 & 1.84 & 0.84 & 0.42 \\
& & & & & & & & \\
4,3 & 4 & MP & 4,4 & 0.56 & 0.79 & 0.71 & 0.48 & 0.12 \\
4,3 & 4 & CV & 3,3 & 0.53 & 0.54 & 0.98 & 1.68 & 0.42 \\
\hline \hline
\end{tabular}

Table 1: Experimental Design and Predictions. $F$ uniform over $[0,100] ; V=$ 400 .

ulations, with $M=4$. We reproduce it in Table 1 , together with the theoretical predictions.

The table dictates the hypotheses to test. The first set concerns turnout rates, $\left\{c_{\mathrm{m}}, c_{\mathrm{M}}\right\}$. First, in all parametrizations, the relative minority/majority turnout $\left(c_{\mathrm{m}} / c_{\mathrm{M}}\right)$ is strictly higher under CV than under MP (H1). Second, under MP the turnout rate is higher for the majority; under CV it is higher for the minority in three of the four parametrizations, and barely lower in the fourth (H2). The second set of hypotheses concerns expected minority victories. First, in all parametrizations the expected share of seats won by the minority is higher under CV than under MP (H3). Second, as a check of the theoretical model, the share varies with the voting rule but for each rule is very close to constant across parametrizations (H4).

We conducted the experiment between August and October 2020, with participants recruited using the Columbia Experimental Laboratory for the Social Sciences (CELSS)' Orsee website ${ }^{12}$. Most subjects were undergraduate students at Columbia University or Barnard College. All sessions were online due to the COVID-19 pandemic: participants received instructions and communicated with experimenters using the Zoom videoconferencing software, and accessed the experiment interface on their personal computer's web browser. The experiment was programmed in z-Tree (Fischbacher, 2007) and run virtually using z-Tree unleashed (Duch et al., 2020). Each experimental session lasted about 90 minutes with average earnings of $\$ 23$. With the exception of a more visual

\footnotetext{
${ }^{12}$ Greiner (2015).
} 
style for the instructions, the experiment developed very similarly to in-person experiments in the lab. ${ }^{13}$

During each session, party sizes were kept fixed, and participants played 15 consecutive rounds each of four treatments, CV and MP for each of $K=2$ and $K=4$. Party affiliations were kept constant within each treatment to facilitate learning but were assigned randomly across treatments. In each round, two groups were formed randomly, each composed of $m$ minority and $M$ majority members. At the end of the round, an outcome screen reported the party affiliations of the $K$ winning candidates and the number of members of each party who had voted. Each participant's final earnings corresponded to the sum of their earnings from one randomly drawn round from each treatment (in addition to the $\$ 5$ show-up fee). For given $m$, either 2 or 3 , we ran two experimental sessions for each of four orders of treatments. ${ }^{14}$ Thus eight sessions were conducted with $m=2$ (12 subjects per session), and eight with $m=3$ (14 subjects per session), for a total of 208 experimental subjects.

\section{Experimental Results}

Figure 2 reports the turnout rates for minority and majority voters in the different treatments, in the upper panels, and the two parties' relative rate in the lower panel. ${ }^{15}$

For all experimental values of $K$ and $m$, minority turnout is higher under CV than under MP. The effect is particularly strong for $m=2$, but remains consistently positive, if more muted, with $m=3$ as well. The difference remains positive even when theory predicts instead a decline in turnout. Interestingly, with one exception, we do not observe the predicted decline in turnout for the majority under $\mathrm{CV}$. The exception is $m=3$ and $K=2$, the parametrization for which the theory predicts the sharpest fall in majority turnout. With these parameters, the majority is certain of one victory and doubts its ability to control the second seat.

The lower panel shows the final effect on relative turnout frequencies: in all cases, the minority's relative turnout rate increases under $\mathrm{CV}$. The theory also predicts that the minority's turnout rate should be lower than the majority's in

\footnotetext{
${ }^{13}$ The online appendix contains a reproduction of the instructions.

${ }^{14}$ The orders were: 1: $\{$ CVK2, MPK2, MPK4, CVK4 $\} ; 2:\{$ MPK2, CVK2, CVK4, MPK4 $\}$; 3: $\{$ MPK4, CVK4, CVK2, MPK2\}; 4: \{CVK4, MPK4, MPK2, CVK2\}.

${ }^{15}$ In all figures below, reported theoretical predictions are calculated on the basis of the realized experimental cost draws.
} 


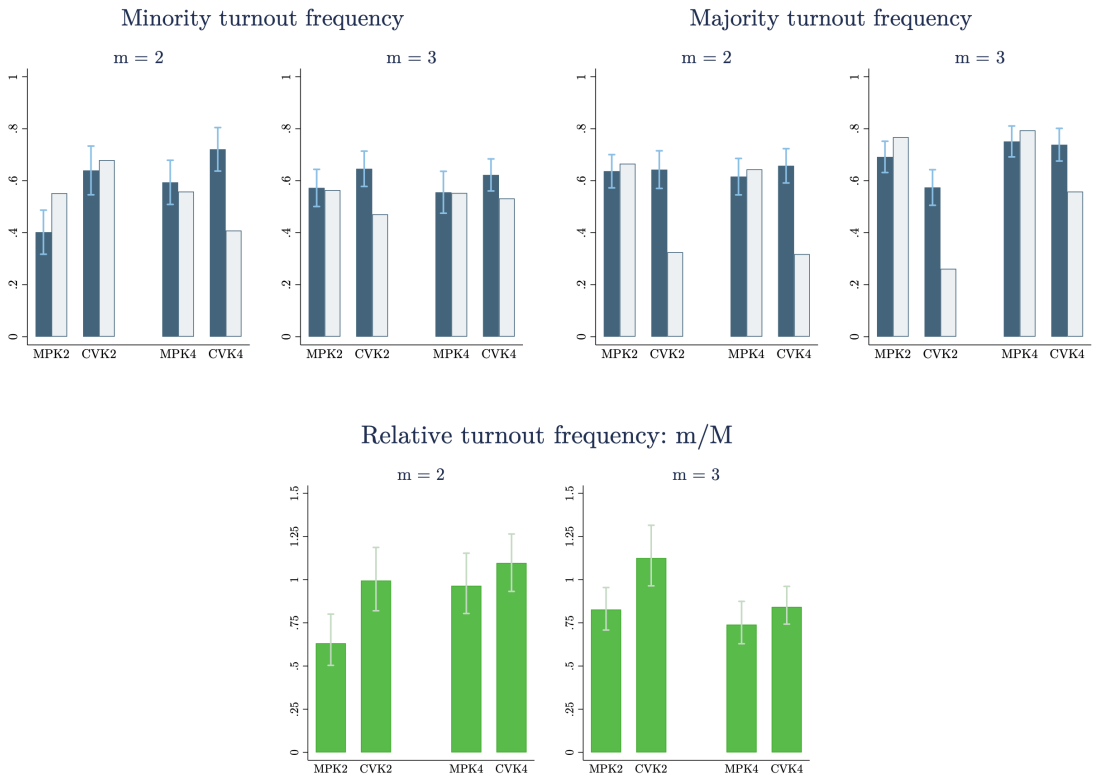

Figure 2: Turnout frequencies. Upper panels: the 95\% CI's reflect standard errors clustered at the individual level. Lower panel: the $95 \%$ CI's are calculated from 10,000 Monte Carlo simulations that allow from correlation in turnout decisions at the individual level. The grey bars in the upper panel correspond to the theory.

all MP treatments, higher in three of the four CV treatments, and barely lower in the fourth. The comparative prediction is again satisfied in all cases.

The evidence from the figure is confirmed by the statistical analysis. In the first two columns of Table 2, we regress subjects' turnout decisions on each subject's voting cost realization and on a series of dummy variables, reflecting $K$, $m$, the voting system, and all cross effects among the three variables, controlling for the round number and the order of treatments in the session. The Table reports the estimation of a linear probability model; results from a probit model are fully consistent and are reported in the appendix.

The first column refers to the minority. Under MP, the increase in the minority's relative size from $m=2$ to $m=3$ increases turnout, and so does the increase in the number of seats from $K=2$ to $K=4$, although the two effects are muted when they occur together. The most interesting result is the strongly positive effect of $\mathrm{CV}$, especially but not only when $m$ is small and $K$ is small. 
Table 2: Turnout and Minority Victories.

\begin{tabular}{|c|c|c|c|}
\hline & Turnout: Minority & Turnout: Majority & \% Seats: Minority \\
\hline $\mathrm{K}=4$ & $\begin{array}{c}0.184 \\
(0.052) \\
{[0.000]}\end{array}$ & $\begin{array}{l}-0.002 \\
(0.033) \\
{[0.949]}\end{array}$ & $\begin{array}{c}0.049 \\
(0.026) \\
{[0.065]}\end{array}$ \\
\hline $\mathrm{m}=3$ & $\begin{array}{c}0.171 \\
(0.052) \\
{[0.001]}\end{array}$ & $\begin{array}{c}0.083 \\
(0.044) \\
{[0.064]}\end{array}$ & $\begin{array}{c}0.100 \\
(0.029) \\
{[0.001]}\end{array}$ \\
\hline $\mathrm{CV}$ & $\begin{array}{c}0.236 \\
(0.061) \\
{[0.000]}\end{array}$ & $\begin{array}{c}0.008 \\
(0.035) \\
{[0.810]}\end{array}$ & $\begin{array}{c}0.158 \\
(0.025) \\
{[0.000]}\end{array}$ \\
\hline$(\mathrm{K}=4) \times(m=3)$ & $\begin{array}{c}-0.199 \\
(0.069) \\
{[0.004]}\end{array}$ & $\begin{array}{c}0.048 \\
(0.048) \\
{[0.318]}\end{array}$ & $\begin{array}{l}-0.122 \\
(0.040) \\
{[0.002]}\end{array}$ \\
\hline$(\mathrm{K}=4) \times C V$ & $\begin{array}{l}-0.087 \\
(0.082) \\
{[0.291]}\end{array}$ & $\begin{array}{c}0.020 \\
(0.045) \\
{[0.657]}\end{array}$ & $\begin{array}{c}0.041 \\
(0.033) \\
{[0.215]}\end{array}$ \\
\hline$(\mathrm{m}=3) \times C V$ & $\begin{array}{l}-0.149 \\
(0.078) \\
{[0.058]}\end{array}$ & $\begin{array}{l}-0.137 \\
(0.052) \\
{[0.009]}\end{array}$ & $\begin{array}{c}0.037 \\
(0.037) \\
{[0.308]}\end{array}$ \\
\hline$(\mathrm{K}=4) \times(m=3) \times C V$ & $\begin{array}{c}0.065 \\
(0.104) \\
{[0.537]}\end{array}$ & $\begin{array}{c}0.082 \\
(0.066) \\
{[0.218]}\end{array}$ & $\begin{array}{l}-0.019 \\
(0.048) \\
{[0.695]}\end{array}$ \\
\hline Treatment order $=2$ & $\begin{array}{c}-0.024 \\
(0.044) \\
{[0.579]}\end{array}$ & $\begin{array}{c}0.033 \\
(0.045) \\
{[0.456]}\end{array}$ & $\begin{array}{c}-0.012 \\
(0.016) \\
{[0.441]}\end{array}$ \\
\hline Treatment order $=3$ & $\begin{array}{c}0.044 \\
(0.043) \\
{[0.304]}\end{array}$ & $\begin{array}{c}0.025 \\
(0.045) \\
{[0.581]}\end{array}$ & $\begin{array}{c}0.011 \\
(0.016) \\
{[0.505]}\end{array}$ \\
\hline Treatment order $=4$ & $\begin{array}{c}0.026 \\
(0.046) \\
{[0.574]}\end{array}$ & $\begin{array}{c}0.011 \\
(0.049) \\
{[0.824]}\end{array}$ & $\begin{array}{c}0.021 \\
(0.017) \\
{[0.221]}\end{array}$ \\
\hline Round & $\begin{array}{c}-0.007 \\
(0.002) \\
{[0.000]}\end{array}$ & $\begin{array}{l}-0.005 \\
(0.001) \\
{[0.000]}\end{array}$ & $\begin{array}{c}0.001 \\
(0.001) \\
{[0.392]}\end{array}$ \\
\hline Voting Cost & $\begin{array}{c}-0.008 \\
(0.000) \\
{[0.000]}\end{array}$ & $\begin{array}{l}-0.008 \\
(0.000) \\
{[0.000]}\end{array}$ & \\
\hline Constant & $\begin{array}{c}0.862 \\
(0.049) \\
{[0.000]}\end{array}$ & $\begin{array}{l}1.039 \\
(0.045) \\
{[0.000]}\end{array}$ & $\begin{array}{c}0.092 \\
(0.023) \\
{[0.000]}\end{array}$ \\
\hline $\begin{array}{l}\text { Observations } \\
R^{2}\end{array}$ & $\begin{array}{l}4800 \\
0.276\end{array}$ & $\begin{array}{l}7680 \\
0.246\end{array}$ & $\begin{array}{l}1920 \\
0.148\end{array}$ \\
\hline \multicolumn{4}{|c|}{$\begin{array}{l}\text { Regressions follow the specification: } \\
\qquad \mathrm{Y}_{i, r}=\beta_{0}+\beta_{1} T_{r}+g X_{i, r}+\epsilon_{i, r} \\
\text { where } T \text { is a vector with dummies for the three treatment effects }(m=3, \mathrm{CV}, K=4) \text { and all their } \\
\text { interactions, by round, and } X \text { is the vector of controls reported in the bottom half of the table. } Y_{i, r} \\
\text { is a binary }\{0,1\} \text { variable. In columns } 1 \text { and } 2 \text {, it captures voting in round } r \text { for individual } i \text {, in } \\
\text { column } 3 \text {, the event of a minority victory in round } r \text { in group } i \text {. Standard errors for columns } 1 \text { and } 2 \\
\text { are clustered at the individual level. Standard errors for column } 3 \text { are clustered at the }(\mathrm{M}+\mathrm{m}) \text { group } \\
\text { level. The excluded case is } \mathrm{m}=2, \mathrm{~K}=2, \mathrm{MP} \text {, with treatment order }\{C V K 2, M P K 2, M P K 4, C V K 4\}\end{array}$} \\
\hline
\end{tabular}


The order of treatments has no detectable effect, while experience (or fatigue) at later experimental rounds causes a significant but quantitatively small decline in turnout.

The second column refers to the majority. Under MP, the regression finds a small and only marginally significant increase in turnout with $m=3$. Under $\mathrm{CV}$, there is a decline in turnout in the $m=3, K=2$ case, but majority turnout remains otherwise relatively constant, regardless of the voting system or the values of $K$ and $m$. For the majority too we find no effect of treatment order and a small significant decline in turnout at later rounds.

Summarizing then, CV increases the minority's turnout, both in absolute terms and relative to the majority, supporting both hypotheses $\mathrm{H} 1$ and $\mathrm{H} 2$. The most noticeable deviation from the theory is the majority's persistently high turnout under CV. ${ }^{16}$

These results invite a natural question: CV affects positively the minority's propensity to vote, but does the aggregate effect mirror a widespread change in behavior, or the changed attitude of a few outliers? We leave the discussion of individual behavior to the appendix, but note there that the minority's higher propensity to vote under $\mathrm{CV}$ operates throughout the distribution of individual cutpoints: the move to CV causes a shift rightward of the whole distribution. For the majority, on the other hand, the impact of $\mathrm{CV}$ on individual cutpoints is barely noticeable, with the one exception of $m=3$ and $K=2$, when we see a consistent decline in voting throughout the majority's cutpoint distribution.

Did CV help the minority secure more seats? Figure 3 shows that the answer is positive.

For every parametrization, CV increases the fraction of minority victories, and does so very significantly, a result confirmed by the third column of Table $2 .{ }^{17}$ The data strongly support hypothesis H3. Note that, as predicted, the share of minority victories remains under $50 \%$ in all cases.

As for hypothesis H4, supported too is the prediction that the differences in minority victories should be larger across voting rules, for given parametrization, than across parametrizations, for given voting rule. The point prediction of constant share of minority victories across parametrizations, for given voting

\footnotetext{
${ }^{16} \mathrm{As}$ a result, total turnout, predicted to fall under $\mathrm{CV}$, remains in fact constant in the lab. We discuss the data on total turnout in the appendix.

${ }^{17}$ As expected, minority victories also increase with the minority size $(m=3)$. In these regressions again there is no effect of treatment order, and neither is there a change from earlier to later rounds, reflecting the previous finding of a parallel and equally small decline in turnout for both parties as the sessions proceeded.
} 


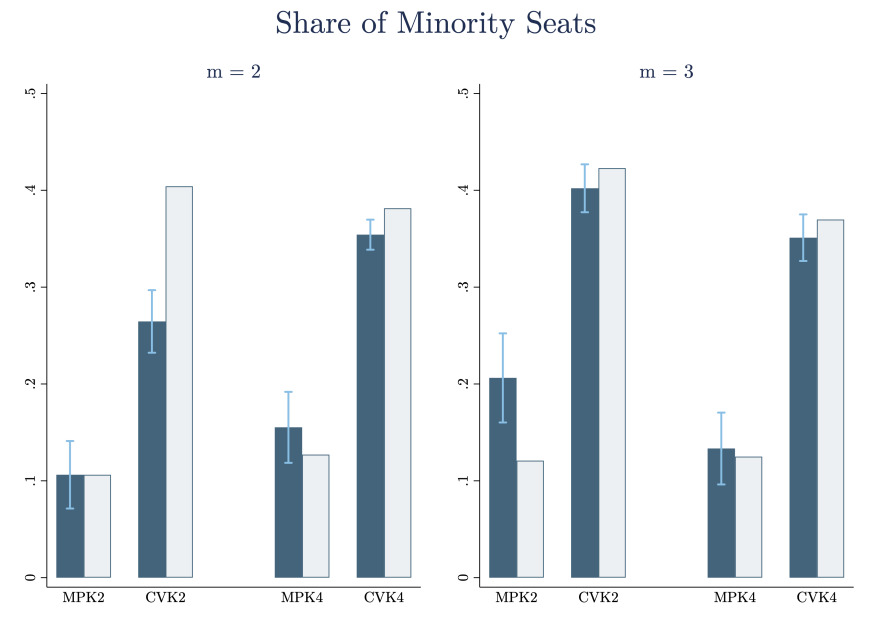

Figure 3: Share of seats won by the minority. Blue columns correspond to the data, grey to the theory. The $95 \%$ CI's are calculated from standard errors clustered at the level of the voting group.

rule, fares slightly less well, with the largest exception the fewer than expected successes of the minority under CV when $K=2$ and $m=2$, reflecting the unexpected high turnout of the majority in this treatment. Even in this case, however, the share of minority seats is more than double what it is under MP.

\section{Conclusions}

As we write, debates over voting rights rage in Congress, in state legislatures, in the courts, in the media. Initiatives aimed at limiting access to the polls and the prospect of partisan redistricting following the 2020 census increase fears of disenfranchisement. Encouraging minority turnout and making the political process more robust to gerrymandering are high priorities. Voting rules like CV have the potential to help both. In the lab, such potential is fulfilled. 


\section{$7 \quad$ References}

Arzumanyan, M. and M Polborn, 2017, "Costly voting with multiple candidates under plurality rule", Games and Economic Behavior, 106, 38-50.

Bowler, S., D. Brockington, and T. Donovan, 2001, "Election Systems and Voter Turnout: Experiments in the United States", Journal of Politics, 63, 902-915.

Bowler, S., T. Donovan, and D. Farrell, 1999, "Party Strategy and Voter Organization under Cumulative Voting in Victorian England", Political Studies, XLVII, 906-917.

Bowler, S., T. Donovan, and D. Brockington, 2003, Electoral Reform and Minority Representation: Local Experiments with Alternative Elections, Ohio State University Press.

Brams, S., 1975, Game Theory and Politics, New York: Free Press.

Brockington, D., T. Donovan, S. Bowler, and R. Brischetto, 1998, "Minority Representation under Cumulative and Limited Voting", Journal of Politics, 60, 1108-25.

Cole, A., 1950, "Legal and Mathematical Aspects of Cumulative Voting", South Carolina Law Review, 2, 225-244.

Cooper, D., and A. Zillante, 2012, "A Comparison of Cumulative Voting and Generalized Plurality Voting", Public Choice 150, 363-83.

Dodgson, Charles, 1884, The Principles of Parliamentary Representation, London, Harrison and Sons.

Duch, M. L., Grossmann, M. R. P. and Lauer, T., 2020, "z-Tree unleashed: A novel client-integrating architecture for conducting z-Tree experiments over the Internet", Journal of Behavioral and Experimental Finance, 28.

Engstrom, R., 2010, "Cumulative and Limited Voting: Minority Electoral Opportunities and More", Saint Louis University Public Law Review 30, 97-138.

Fischbacher, U., 2007, "z-Tree: Zurich toolbox for ready-made economic experiments", Experimental Economics 10, 171-178.

Gerber, E.., R. Morton, and T. Rietz, 1998, "Minority Representation in Multimember Districts", American Political Science Review 92, 127-44.

Glasser, G., 1959, "Game Theory and Cumulative Voting for Corporate Directors", Management Science, 5, 143-215.

Glazer, A., D. Glazer and B. Grofman, 1984, "Cumulative Voting in Corporate Elections: Introducing Strategy in the Equation", South Carolina Law Review, 35, 295-309. 
Goldburg, C., 1994, "The Accuracy of Game Theory Predictions for Political Behavior: Cumulative Voting in Illinois Revisited", Journal of Politics, 56, 885900

Greiner, B., 2015, "Subject Pool Recruitment Procedures: Organizing Experiments with ORSEE", Journal of the Economic Science Association, 1, 114125 .

Grofman, B., L. Handley, and R. Niemi, 1992, Minority Representation and the Quest for Voting Equality, Cambridge: Cambridge University Press.

Guinier, Lani, 1994, The Tyranny of the Majority, Free Press: New York, NY.

Herrera, H., M. Morelli and T. Palfrey, 2014, "Turnout and Power Sharing", Economic Journal, 124, F131-F162.

Ledyard, J., 1984, "The pure theory of large two-candidate elections", Public Choice, 44, 7-41.

Levine, D., \& Palfrey, T., 2007, "The Paradox of Voter Participation? A Laboratory Study", American Political Science Review, 101, 143-158.

Levine, D. and A. Mattozzi, 2020, "Voter Turnout with Peer Punishment", American Economic Review, 110, 3298-3314.

Obama, B., 2020, A Promised Land, Random House: New York, NY.

Palfrey, T. and H. Rosenthal, 1983, "A Strategic Calculus of Voting", Public Choice, 41, 7-53.

Pew Research Center, 2013, "The Growing Electoral Clout of Blacks Is Driven by Turnout, Not Demographics."

Pildes, R. and K. Donoghue, 1995, "Cumulative Voting in the United States", University of Chicago Legal Forum: Vol. 1995, Article 10.

Riker, W. and P. Ordeshook, 1968, "A Theory of the Calculus of Voting", American Political Science Review, 62, 25-42.

Sawyer J. and D. MacRae, 1962, "Game Theory and Cumulative Voting in Illinois: 1902-1954", American Political Science Review, 56, 936-946.

US Census Bureau, 2017, Current Population Survey Voting and Registration Supplements: 1980-2016. 